attention-deficit hyperactivity disorder symptoms. Arch Gen Psychiatry September 1997;54:857-864). (Reprints: Christopher Gillberg MD, PhD, Department of Child and Adolescent Psychiatry, University of Goteborg, Annedals Clinics, S 41345 Goteborg, Sweden).

COMMENT. Long-term treatment of ADHD with amphetamine may result in improved behavior and learning after 15 months trial, and side effects are generally mild. Trials in ADHD with less comorbidity would be expected to show even greater beneficial effects.

A collaborative multimodal treatment study of children with ADHD, the MTA, is described by NIMH collaborators. (Jensen PS et al. Arch Gen Psychiatry Sept 1997;54:865-870). It examines long-term effectiveness of medication vs behavioral treatment vs both in 576 children (age, 7-9 years) with ADHD (96 at each of 6 sites) treated for 14 months and reassessed periodically for 24 months. The first patients were enrolled in 1994 and the last will complete the trial in 1998. Pediatric psychopharmacology is receiving a needed boost from this study initiated by the NIMH, and research findings from short-term trials will be tested in more practical, clinically meaningful settings.

\title{
SOMATOSENSORY FUNCTION IN ADHD
}

Somatosensory evoked potentials (SEP) and tactile function were tested in $49 \mathrm{ADHD}$ children and 49 controls at the Hebrew University, Jerusalem, Israel. Six sensory integration and praxis tests were used to examine suprathreshold tactile perception. These included finger identification, graphesthesia, localization of tactile stimuli, manual form perception, and kinesthesia. ADHD children performed poorly on these suprathreshold somatosensory tests but within normal limits on a smooth vs rough texture discrimination threshold task. The SEP central components were larger in amplitude in ADHD children compared to controls, which supports the theory of cortical neuronal hyperactivity in ADHD. (Parush S, Sohmer H, Steinberg A, Kaitz M. Somatosensory functioning in children with attention deficit hyperactivity disorder. Dev Med Child Neurol July 1997;39:464-468). (Respond: Marsha Kaitz PhD, Department of Psychology, Hebrew University, 91905, Jerusalem, Israel),

COMMENT. Somatosensory functioning is impaired in ADHD, lending credence to the Ayres sensory integration therapies. Testing for cortical sensory function is included in the pediatric neurology evaluation of children with ADHD.

\section{MEGALENCEPHALY AND DEVELOPMENTAL DELAY}

Neurodevelopmental function, language, academic achievement, visuomotor integration, and motor function were evaluated in 20 nonreferred children, aged 6 to 15 years, with idiopathic megalencephaly (>98th percentile) from a suburban practice, and compared to 19 siblings with normal heads and 16 age-matched controls, at the Olson Huff Center for Child Development, Thoms Rehabilitation Hospital, Asheville, North Carolina. Megalencephaly was associated with impaired performance on upper limb motor proficiency, visuomotor integration, response speed, coordination, and increased mirror movements and other neurologic soft signs. Naming fluency was weak, but receptive vocabulary and academic performance were not affected. (Sandler AD, Knudsen MW, Brown TT, Christian RM Jr. Neurodevelopmental dysfunction among nonreferred children with idiopathic 